\title{
Waste from the coal extraction process as raw material for the construction industry
}

\author{
N. Quaranta ${ }^{1}$, M. Caligaris ${ }^{1}$, H. López ${ }^{1}$, M. Unsen ${ }^{1}$, M. Carrasco ${ }^{2}$, \\ R. Grether ${ }^{2}$, M. Suarez ${ }^{2}$ \& L. Beltramini ${ }^{2}$ \\ ${ }^{1}$ Universidad Tecnológica Nacional. Facultad Regional San Nicolás, \\ Argentina \\ ${ }^{2}$ Universidad Tecnológica Nacional. Facultad Regional Santa Fe, \\ Argentina
}

\begin{abstract}
During mineral mining, huge quantities of waste are produced. This waste is usually placed in the open air, near the deposits, with the environmental consequences this situation implies.

The construction industry and its auxiliaries can receive waste and by-products. As these industries handle materials on a large scale they can include an important percentage of waste in their compositions.

In the present work the feasibility of utilization by the construction industry of waste originating during the coal extraction process as a raw material was studied.

The materials, as received from the mine, were characterized as usual. From analysis of the results it is concluded that the waste can be used without any additives, but subject to a previous milling process in order to reduce the bigger pieces so as to prepare adequate mixtures for the compacting process.

In a previous work some waste from the process was analyzed: ashes, mud and sterile material. As the stored quantity of the sterile material is noticeably higher and its characterization shows the possibility of using it to produce dense bodies, only this residue is studied in this work.

The "steriles" were ground and mixtures with different particle size distribution were prepared. These powders, with $12 \% \mathrm{H}_{2} \mathrm{O}$ and without other additives, were uniaxially pressed in order to obtain samples that were heat treated at $850^{\circ} \mathrm{C}$.

The samples obtained had good properties related to color, edges and surface finish. They were characterized by several techniques.

Keywords: waste, coal extraction, construction, recycling, ceramic bricks.
\end{abstract}




\section{Introduction}

Waste products are such things or substances generated during a consumption or productive activity, which have not direct interest in the main activity: industries must get rid of them and be in charge of their disposal. It is not possible to continue with the present waste generation without causing a collapse of production or of the planet habitat. Under these circumstances, there are two possible and simultaneous choices: the generation reduction and the reusing or recycling. Reusing consists of redirecting the waste materials to new production processes, instead of sending them to the waste flow. Usually, some changes in the production final steps are needed in order to transform the waste into secondary raw materials for the same industry or into raw materials for others.

It is important to mention that within the general classification there exist three kinds of waste: special, not special and inert [1]. The special waste products are those which, due to their dangerous or toxic properties and their concentration, need specific treatments and strict controls to prevent pernicious effects. The waste that never suffers any physicochemical change, under usual disposal conditions, is called inert waste. Non special waste is that which can go through changes and result in products that are not potentially dangerous.

In this work the feasibility of utilization of waste originating during the coal extraction process as raw material for the construction industry is studied.

During the process, the gross coal extracted from the mine is sent to a purification station and put on a vibrating sieve where particles bigger than 150 $\mathrm{mm}$ are separated to be milled. All the material is stored in silos until it is used. From there, the mineral is taken to a sieve and separated in two parts, one constituted by particles bigger than $20 \mathrm{~mm}$ and the other by smaller particles.

The fraction of bigger particles is introduced in a dense medium consisting of pulverized magnetite and water. By gravity, a floating material composed of waste and coal and a decanted waste material, called steriles, are separated. The fraction of particles smaller than $20 \mathrm{~mm}$ is introduced in a cyclonic decanter that also works with a mixture of magnetite and water, but here the floating material is separated by centrifugation. The heavier material is separated through the inferior exits of the cyclone and constitutes other fractions called steriles. The decanted waste is disposed in opencast stocks in the purification plant field. In both cases, the dense medium waste content is discharged from the decanters and is taken to a tank for mud sedimentation. This mud is later disposed in opencast pools, being another waste of the process.

In power plants, coal is used as fuel producing a large amount of ashes: coarse and fly ash. Coarse ashes are produced from the material melted during combustion, which is removed as liquid slag and solidifies as grains when cooled with water. This material constitutes other waste of the process.

In this work the waste called steriles produced during the coal extraction process in Rio Turbio coal mine, Santa Cruz province, Argentina, is studied. The other mentioned waste was analyzed in a previous work [2]. Although, according to the previously presented classification, it is inert waste, it's stock produces serious environmental problems in the area. 


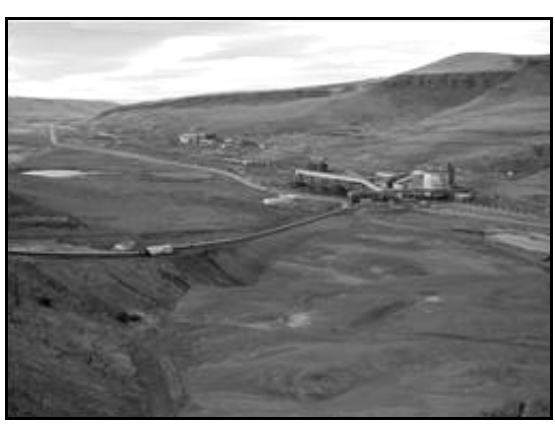

Figure 1: Steriles stock.

Figure 1 shows a view of the purification plant from the highest point of the steriles stock, and the appearance of the deposits of agglomerated particles. Very different sizes are observed.

Preliminary studies of this waste have been made, focusing on it's utilization in the field of the construction industry, specifically in road surfaces where it was included or in other materials such as cement or concrete. The obtained results indicated that these materials must be heat treated and stabilized with lime in order to fit their physical characteristics and mechanical behaviour within the expected parameters for materials to be used as structural bases of road surfaces [3].

\section{Experimental}

\subsection{Waste and products characterization}

The powders to be used as raw material for the dense bodies' production and the fired samples obtained were characterized by several techniques: optical and scanning electron microscopies (SEM), electron diffraction analysis X-ray (EDAX), X-ray diffraction (XRD), particle size distribution, permanent linear expansion and Vickers microhardness measurements.

The SEM analyses were carried out through a Phillips 515 scanning electronic microscope with an X-ray detector (EDAX-Phoenix).

The optical observations were made with Zeiss-Axiotech equipment with a Donpisha 3CCD camera and image scanner.

The X-ray diffraction spectra of the powdered samples were obtained for $2 \theta$ values between $10^{\circ}$ and $60^{\circ}$ with Phillips PW 3710 equipment, with $\mathrm{CuK \alpha}$ radiation and $\mathrm{Ni}$ filter. The operation conditions were $40 \mathrm{kV}, 20 \mathrm{~mA}$. The obtained patterns were analyzed using ASTM Standard files (pcpdfwin files).

The hardness analyses were made with a Vickers indenter in an HMV-2000 Shimatzu equipment, using loads of $200 \mathrm{~g}$ during $30 \mathrm{sec}$ in all cases.

The granulometric characterization was carried out by dry and wet way methods according to VN-E7-65 and VN-E1-65 Standards respectively. The waste materials, as received from the deposits, were subjected in a first step to a 
disintegration process at $70^{\circ} \mathrm{C}$ which generates the coarse particulates dissociation. The particle size distribution essays were made using these powders. In a second step the waste was milled to particle sizes smaller than 600 $\mu \mathrm{m}$, in order to select the fractions needed to prepare the bodies.

\subsection{Compact samples preparation}

The compact bodies were obtained starting from ground steriles separated by particle size. Mixtures with 30\% particles between 600 and $300 \mu \mathrm{m}, 40 \%$ between 300 and $150 \mu \mathrm{m}$ and $30 \%$ between 150 and $75 \mu \mathrm{m}$ were prepared. These powders, with $12 \% \mathrm{H}_{2} \mathrm{O}$ and without other additives, were uniaxially pressed $(70 \mathrm{MPa})$ in order to obtain samples of $70 \mathrm{~mm} \times 40 \mathrm{~mm} \times 10 \mathrm{~mm}$.

After adjusting parameters of preparation and treatment of those samples, pieces as big as common bricks were prepared.

The samples were heat treated at $850^{\circ} \mathrm{C}$ for 6 hours in order to obtain sintered dense bodies. From now onwards small pieces will be called probes and the others will be called bricks.

Obtained sintered bodies were prepared for characterization. Pieces of about $1 \mathrm{~cm}^{2}$ were cut, squeezed in resin and then polished with different papers and pastes (up to diamond $1 \mu \mathrm{m}$ ) in order to reach a proper surface for microscopic observations and microhardness measurements.
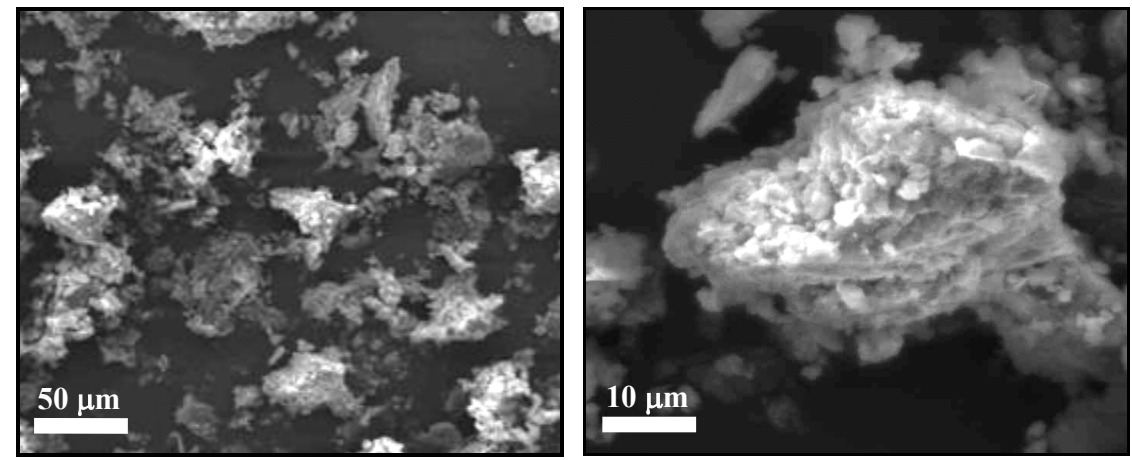

Figure 2: $\quad$ SEM microphotographs of esteriles.

\section{Results and discussion}

\subsection{Steriles characterization}

Figure 2 shows the morphological analysis carried out on the samples by scanning electron microscopy. As it can be observed, the particles have not, in general, uniform morphologies with the presence of crystalline cut planes, edges and angles. The bigger particles come from the joining of smaller ones, constituting agglomerates. 
Table 1: $\quad$ EDAX analysis of the particles.

\begin{tabular}{|l|l|l|l|l|l|l|l|l|}
\hline Oxide & $\mathrm{Na}_{2} \mathrm{O}$ & $\mathrm{MgO}$ & $\mathrm{Al}_{2} \mathrm{O}_{3}$ & $\mathrm{SiO}_{2}$ & $\mathrm{~K}_{2} \mathrm{O}$ & $\mathrm{CaO}$ & $\mathrm{TiO}_{2}$ & $\mathrm{FeO}$ \\
\hline $\mathbf{\%}$ & 2.3 & 3.3 & 27.2 & 62.5 & 0.9 & 1.1 & 0.6 & 2.1 \\
\hline
\end{tabular}

In Table 1 the semi quantitative chemical analysis (EDAX) of the samples can be observed.

EDAX reveals the $\mathrm{Al}$ and $\mathrm{Si}$ oxides are the major part, being present other oxides such as $\mathrm{Na}_{2} \mathrm{O}$ and $\mathrm{K}_{2} \mathrm{O}$ that are important during the process of sintering dense bodies, although they are in small proportion. These oxides contribute to the liquid phase formation, facilitating the inter-particles necks during the samples sintering.

It can be observed that, in the calculations of compositions of these materials as percentage, the carbon present in the samples, which appears in a high proportion, was not considered. In several essays, it was determined that the carbon content was approximately $20 \%$. The reason for this calculation is that carbon will be eliminated in the composition of the sintered dense bodies during its production, which is another objective of this study. The percentages shown in Table 1 are used to determine the probable sintering temperature of the materials, taking into account the corresponding ternary diagrams.

According to these analysis results, the materials composition can be localized in the phase equilibrium diagram $\mathrm{Al}_{2} \mathrm{O}_{3}, \mathrm{Na}_{2} \mathrm{O}, \mathrm{SiO}_{2}$ in the compatibility triangle defined by the oxides $\mathrm{SiO}_{2}, \mathrm{Na}_{2} \mathrm{O} . \mathrm{Al}_{2} \mathrm{O}_{3} \cdot 6 \mathrm{SiO}_{2}$ (albite), $3 \mathrm{Al}_{2} \mathrm{O}_{3} .2 \mathrm{SiO}_{2}$ (mullite), and in the phase equilibrium diagram $\mathrm{Al}_{2} \mathrm{O}_{3}, \mathrm{MgO}, \mathrm{SiO}_{2}$, in the compatibility triangle defined by the oxides $\mathrm{SiO}_{2}, 2 \mathrm{MgO} .2 \mathrm{Al}_{2} \mathrm{O}_{3} .5 \mathrm{SiO}_{2}$ (cordierite), $3 \mathrm{Al}_{2} \mathrm{O}_{3} \cdot 2 \mathrm{SiO}_{2}$ (mullite). For this study the oxides with similar behaviour were considered added. In this way the $\mathrm{K}_{2} \mathrm{O}$ is added to the $\mathrm{Na}_{2} \mathrm{O}$ and the $\mathrm{CaO}$ is added to the $\mathrm{MgO}$.

The quaternary invariant point must have a temperature not higher than the temperature of the ternary invariant point of lowest temperature. Therefore, the temperature of the first liquid formation in the considered material would be lower than $1050{ }^{\circ} \mathrm{C}$. If this last value is considered for calculations, the sintering temperature is determined to be lower than $785^{\circ} \mathrm{C}$. For this reason, the working temperature for the production of sintered dense bodies was established to be $850^{\circ} \mathrm{C}$, in order to be sure the sintering process takes place.

The X-Ray pattern obtained of the waste powders is shown in Figure 3. The presence of three crystalline phases, identified as 1,2 and 3 in the figure, is revealed. The phase 1 corresponds to $\mathrm{SiO}_{2}$-quartz (pdf 87-2056), the phase 2 to $\mathrm{Al}_{2} \mathrm{Si}_{2} \mathrm{O}_{5}(\mathrm{OH})_{4}$-caolinite (pdf 83-0971), and the phase 3 to $\mathrm{K}_{0,2} \mathrm{Na}_{0,8} \mathrm{AlSi}_{3} \mathrm{O}_{8}$-albite (pdf 83-2215).

In the results of the granulometric characterization essays, it can be observed that the essay carried out by dry way method reveals a material with bigger particle sizes than those determined by wet way method. This is due to the presence of agglomerates that are scored as particles of bigger sizes and are then disintegrated in contact with water. 


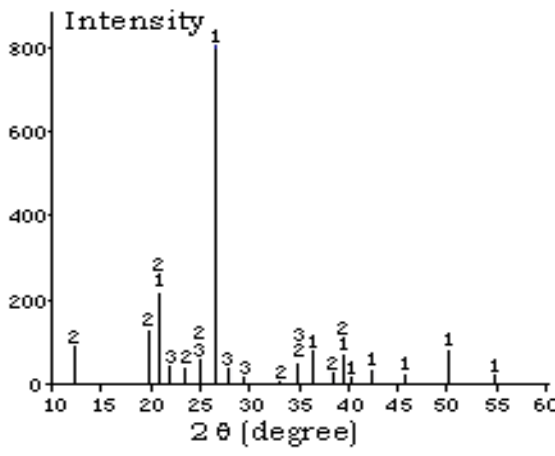

Figure 3: XRD pattern of steriles powder.

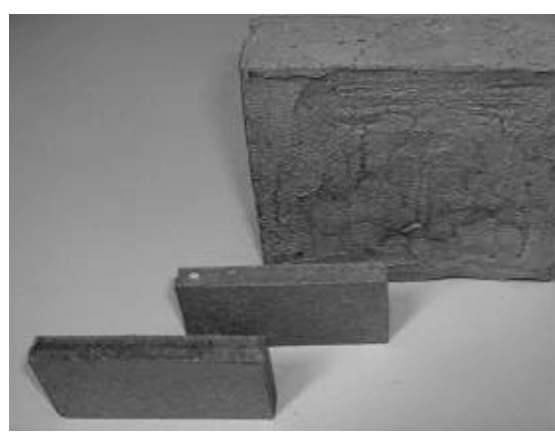

Figure 4: Probes and brick obtained starting from steriles $\left(850^{\circ} \mathrm{C}\right.$ for $\left.6 \mathrm{~h}\right)$.

\subsection{Products characterization}

In the photographs presented in Figure 4 the samples obtained from steriles after a heat treatment at $850^{\circ} \mathrm{C}$ for 6 hours are shown. As it can be observed the samples show good macroscopic characteristics in relation to color uniformity, surface, edges maintenance, etc.

The compact bodies color varied from dark brown in the pieces before firing to beige in the fired pieces. This is due to the carbon loss in the samples.

The weight loss in the samples was $20 \%$, approximately. This corresponds to the loss of the water, added in the powders compacting process, and of part of the carbon content of the waste. Therefore, in the fired pieces there is a remaining carbon content. Inside the samples the color is darker, this can be observed macroscopically if the samples are cut.

The analysis performed by optical microscopy showed differential structures between the zones near the surface and the interior of the pieces. At a superficial level sintered particles and lower porosity are detected. This fact can be observed in Figure 5 (a). Carbon particles were not found in this zone.
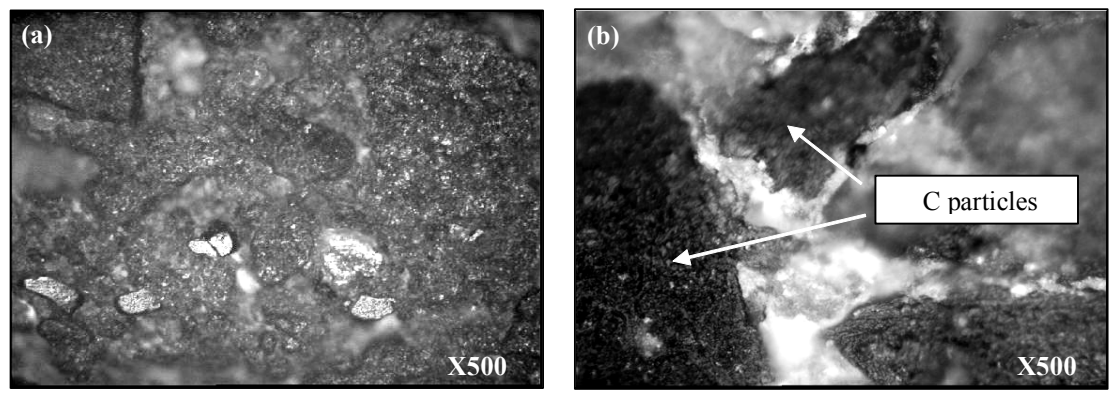

Figure 5: Optical microscopies of the fired probes (a) zone close to the surface. (b) interior zone. 

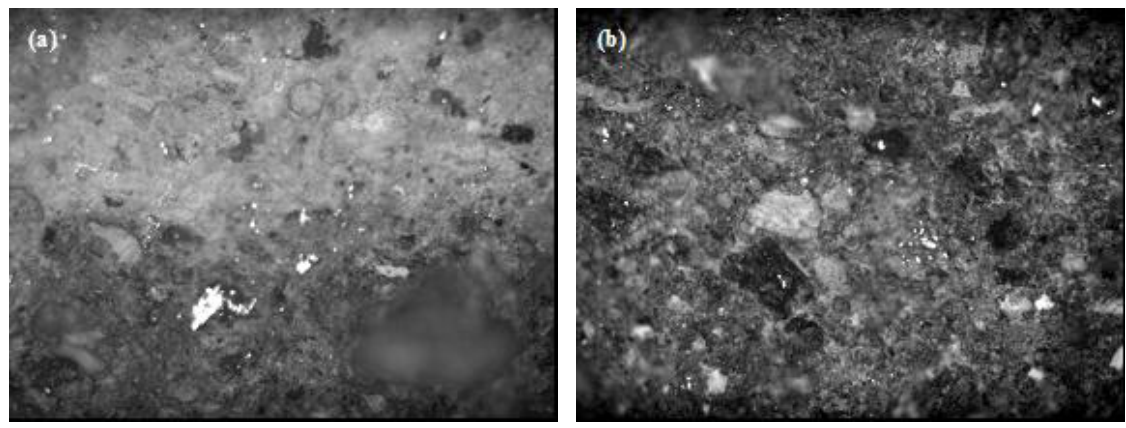

Figure 6: Optical microscopies of the fired bricks (x100) (a) zone close to the surface. (b) interior zone.
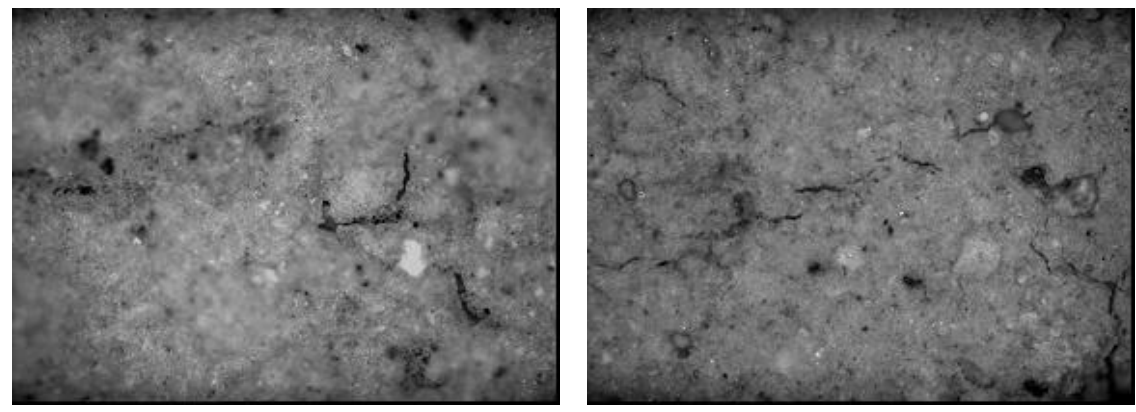

Figure 7: $\quad$ Optical studies of the fired bricks (x100).

In the central area of the samples more porous zones, with low sintering degree of the structure and great presence of carbon particles are observed (Figure $5(\mathrm{~b})$ ).

In Figure 6, optical microscopies of the fired bricks, in the interior zone and in the zone close to the surface are observed, in a transverse section. The region closer to the surface appears lighter, with little amount of pores and carbon particles. A sinterization shell, with uniform thickness along the brick, between $1.6 \mathrm{~mm}$ and $2.2 \mathrm{~mm}$, is observed.

Surface characteristics of probes and bricks are noticeably different, in relation to pores size and quantity and the presence of cracks. The probes have greater porosity without cracks, while bricks show small isolated pores and micro cracks originated on them, as can be seen in Figure 7.

These differences in the sintering degree and porosity between the zones close to the surface and the central area is more remarkable if the samples are analyzed by SEM. Figure 8 shows these mentioned different zones. As it can be seen, the sintering of the compacted particles was reached up to a distance of $600 \mu \mathrm{m}$ from the surface, approximately. Observations with higher magnifications of the zone 
between these two different sectors show the formation of inter-particle necks and the beginning of structural unification as an intermediate step of the process of sintering and densification of the pieces (Figure 9).

The Vickers microhardness analysis of the fired bodies (probes) was made only in the denser zones close to the surface, because in the rest of the sample it was not possible to obtain clear stamps feasible to measure, due to the very low tenacity of these sectors. The obtained microhardness value, average of 10 measurements, with $10 \%$ dispersion, is $\mathrm{Hv}: 892 \mathrm{Kg} / \mathrm{mm}^{2}$. This value is slightly superior to the values found in literature for silicoaluminous materials as cordierite $\left(\sim 840 \mathrm{Kg} / \mathrm{mm}^{2}\right)$, and inferior to the value determined for pure quartz $\left(\sim 1240 \mathrm{Kg} / \mathrm{mm}^{2}\right)[6]$.

In the bricks, the obtained microhardness value, average of 10 measurements in the surface zone, with $6 \%$ dispersion, is $\mathrm{Hv}: 870 \mathrm{Kg} / \mathrm{mm}^{2}$. In the central area the measurements conditions exceed the structure tenacity. For this reason, the load and the time were lowered until measurements could be done properly. When using loads of $100 \mathrm{~g}$ for 20 seconds, a value Hv: $685 \mathrm{Kg} / \mathrm{mm}^{2}$, average of 10 measurements, with $12 \%$ dispersion, was obtained.

The X-Ray patterns of the fired compacts reveal the same crystalline phases present in the original materials, proving that the thermal treatment doesn't produce changes in the crystalline structures.
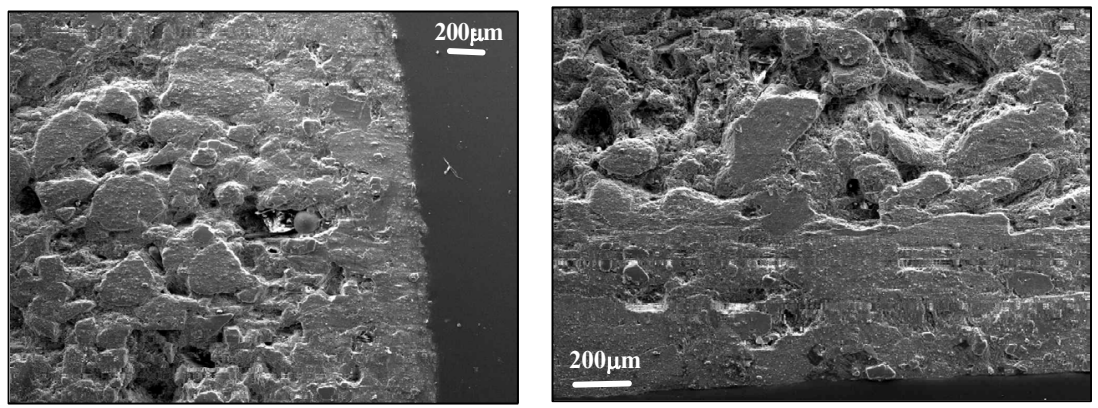

Figure 8: $\quad$ SEM analysis of the fired compacts.

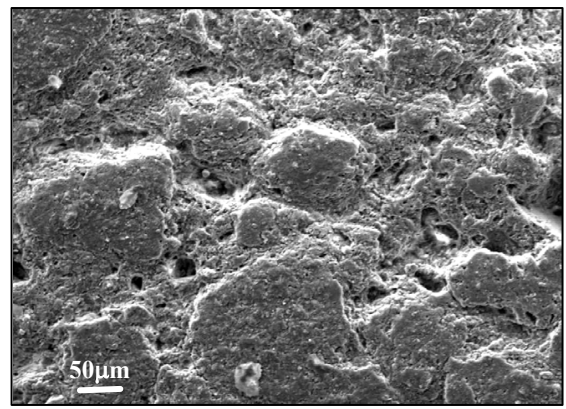

Figure 9: SEM photograph of transition zone between sinterized and nonsinterized areas. 

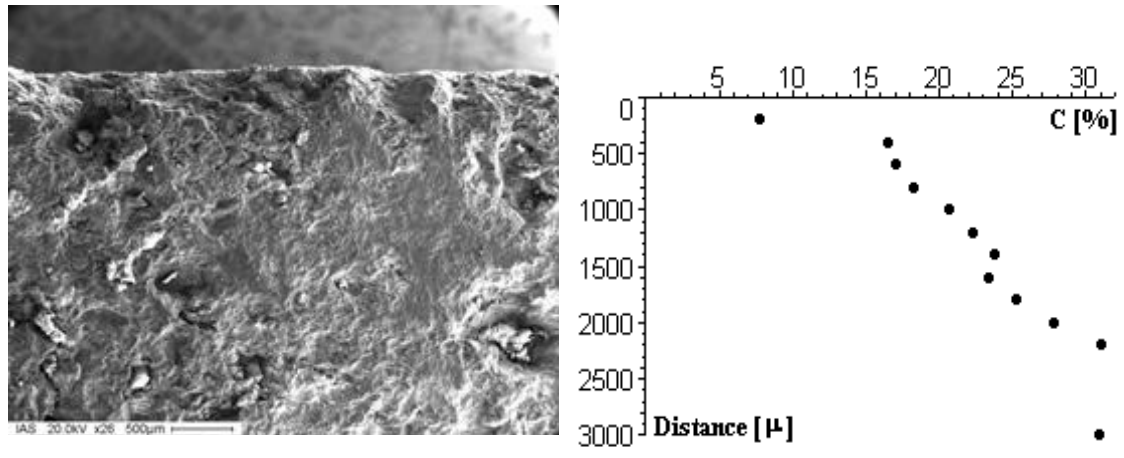

Figure 10: SEM-EDAX analysis of the bricks.

In Figure 10 the results of the SEM - EDAX analysis are presented. In this figure a transverse section of the brick is shown. On the right side, the carbon content percentages from the surface to the central area, in analysis intervals of $200 \mu$, are plotted. Carbon contents of approximately $30 \%$ are determined for distances from the surface greater than $2200 \mu$. This fact is coincident with the sinterization shell determined by optical microscopy.

\section{Conclusions}

It is possible to produce sinterized dense bodies from waste from the coal extraction process. This material is used as it is disposed in the stock sector, after a milling process and a proper selection of particle sizes and thermal treatments.

Small sintered probes, with good superficial and mass properties (color, edges maintenance, porosity, hardness, etc) were obtained.

With the aim of improving the final product quality, different working conditions leading to the complete coal elimination and the complete sinterization of the bodies will be essayed.

Masonry bricks, as big as common building bricks, were also prepared. Pieces of good characteristics, with a sinterized shell of $2 \mathrm{~mm}$ thickness, approximately and carbon contents in the central zone similar to those of the raw material, were obtained.

\section{Acknowledgement}

Support by CIC is gratefully acknowledged.

\section{References}

[1] Castells, X., Reciclaje de Residuos Industriales. Aplicación a la Fabricación de Materiales para la Construcción. Eds Días De Santos S.A. Madrid. Spain. (2000). pp 45. 
[2] Quaranta, N., Caligaris, M., López, H., Unsen, M., Giansiracusa, C., Carrasco, F., Grether, R., Suarez, M, y Beltramini, L. IV Encuentro PROCQMA, Argentine, (2006). Publisher in CD. ISBN13:978-42-0056-7.

[3] Segovia, M., Hillar, P., Zocco, C., Carrasco, M., Proyecto ANR SC 006/2003. III Encuentro PROCQMA, Argentine, (2005). Published in CD.

[4] Osborn, E. and Muan, A., Phase Equilibrium Diagrams of Oxide Systems, Plate 3: System $\mathrm{MgO}-\mathrm{Al}_{2} \mathrm{O}_{3}-\mathrm{SiO}_{2}$. American Ceramic Society and the Edward Orton Jr. Ceramic Foundation, (1960).

[5] Osborn, E. and Muan, A., Phase Equilibrium Diagrams of Oxide Systems, Plate 4: System $\mathrm{Na}_{2} \mathrm{O}-\mathrm{Al}_{2} \mathrm{O}_{3}-\mathrm{SiO}_{2}$. American Ceramic Society and The Edward Orton Jr. Ceramic Foundation, (1960).

[6] McColm, I., Ceramic Hardness. Plenum Press Ed. NY-London. 1990. pp 260 . 